Utah State University

DigitalCommons@USU

$5-2-2019$

\title{
On the Relationship Between North India Summer Monsoon Rainfall and East Equatorial Indian Ocean Warming
}

\author{
Ramesh Kumar Yadav \\ Utah State University \\ Mathew Koll Roxy \\ Indian Institute of Tropical Meterology
}

Follow this and additional works at: https://digitalcommons.usu.edu/psc_stures

Part of the Plant Sciences Commons, and the Soil Science Commons

\section{Recommended Citation \\ Ramesh Kumar Yadav and Mathew Koll Roxy, On the relationship between north india summer monsoon rainfall and east equatorial indian ocean warming, Global and Planetary Change 179 (2019), 23-32.}

This Article is brought to you for free and open access by the Plants, Soils, and Climate Student Works at DigitalCommons@USU. It has been accepted for inclusion in Plants, Soils and Climate Student Research by an authorized administrator of DigitalCommons@USU. For more information, please contact digitalcommons@usu.edu.

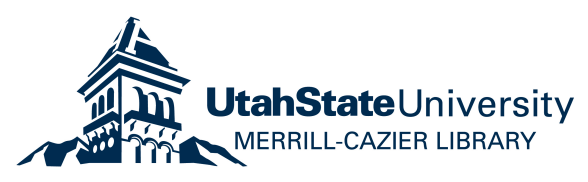




\title{
On the relationship between north India
}

\section{summer monsoon rainfall and east equatorial Indian Ocean warming}

\author{
Ramesh Kumar Yadav ${ }^{1,2}$ and Mathew Koll Roxy ${ }^{2,3}$ \\ ${ }^{1}$ Plants, Soils and Climate Department and Utah Climate Center, Utah State University, Logan, \\ Utah, USA \\ ${ }^{2}$ Indian Institute of Tropical Meteorology, Pashan, Pune, India \\ ${ }^{3}$ NOAA/Pacific Marine Environmental Laboratory, Seattle, Washington, USA
}

Corresponding author address: Ramesh Kumar Yadav, Indian Institute of Tropical Meteorology, Pashan, Pune-411008, India.

E-mail: yadav@tropmet.res.in 


\begin{abstract}
Generally, a strong north India summer-monsoon rainfall (NISR) is associated with anomalous upper troposphere ridge over northwest of India. This ridge triggers anomalous northerly winds over Tibetan Plateau and easterlies over India. The easterly anomaly over India reduces the tropospheric wind shear, while the northerly at Tibetan plateau allows frequent intrusions of high-latitude dry and cold meridional winds to interact with the lower-level relatively warm and moist easterly monsoonal flow, enhancing the NISR. The current study, using a suite of observations, reanalysis products and numerical model sensitivity experiments, explores the changes in NISR, and its association with the warming in the equatorial Indian Ocean.

In the recent two decades (1996-2017), the NISR has been exhibiting a decreasing trend with increased variability, much larger than the earlier period (1979-2000). A possible reason for this is due to the rise in warm sea surface temperature (SST) observed in the east equatorial Indian ocean, which shows a negative correlation to NISR. The current analysis indicates that the warmer SST induce strong convection and associated northward propagating off-equatorial Rossby gyres to the west of the equatorial eastern Indian ocean, spreading the tropospheric heating towards the northeast of India, thereby elevating the geopotential height. This creates upper troposphere low pressure anomaly at the northwest of India. These factors are consistent with the suppression of the NISR, resulting in the observed decreasing trend in the recent decades.
\end{abstract}

KEY WORDS: Indian summer monsoon; North India; deep convection: sea surface temperature; equatorial Indian Ocean; Tibetan Plateau; Rossby wave gyres. 


\section{Introduction}

The South Asian monsoon, especially that over the Indian subcontinent can be considered as one of the strongest and the most significant phenomenon in the tropical climate. Agriculture and the entire ecosystem of the Indian subcontinent depend upon this monsoonal rain, which occurs during June to September (JJAS), also known as Indian summer monsoon (ISM). The northern part of India consists of one of the richest fertile land of the Gangetic Plain and the world's largest population density. North India is home to more than 7 percent of the world's population. The main occupation in this region is agriculture and husbandry, which heavily depends on the variability of the north India summer-monsoon rainfall (NISR). Therefore, the spatial and temporal variations of NISR, manifested in the floods and droughts, have a significant impact on agricultural yields and livelihood of the people living in this region.

The north Indian region, in the proximity of the foot hills of Himalayas, gets heavy rainfall during the summer season (JJAS). The rainfall over north India extending to the foot hills of Himalayas are supposed to be enhanced when the monsoon is in a break phase over central India. During this phase, the monsoon trough shifts northwards from its normal position towards the foothills of Himalayas, while central India is marked by anomalous high pressure. At the upper-level, the large amplitude westerly trough intrudes into the northern parts of India and give rise to heavy rainfall(Ramamurthy 1969, Krishnamurti et al. 1980, Ramaswamy, 1956, 1962, Raman \& Rao 1981). And, also the interaction between the strong monsoonal flows and the high amplitude westerly trough embedded in the westerly jet (Vellore et al. 2014) produces heavy rainfall over north India. 
The inter-annual variability of Indian rainfall is strongly influenced by the El-NiñoSouthern Oscillation (ENSO; Kumar et al. 1999, Ashok et al. 2004, Yadav, 2009a, 2009b), the Indian Ocean Dipole Mode (Saji et al. 1999, Webster et al. 1999, Ashok et al. 2004, Crétat et al. 2017), the tropical Atlantic/Atlantic Niño (Goswami et al. 2006, Kucharski et al. 2008, Yadav 2017a, Yadav et al. 2018) and the surface temperature/pressure over the Middle-East (Yadav, 2016, 2017b). The summer monsoon rainfall over the central and northern parts of India has been showing a decreasing trend since the 1950s, according to several studies (Annamalai et al. 2013, Ratna et al. 2016, Ramanathan et al. 2005, Roxy et al. 2015). Ramanathan et al. (2005) attribute the drying trend to a change in meridional temperature gradients, due to increased aerosols concentrations. Meanwhile, Annamalai, et al. (2013) argue that the SST warming over the tropical west Pacific causes a drying trend over South Asia due to changes in the atmospheric circulation, by which drier, cooler air is advected from northeast India towards Bay-of-Bengal and the Indian subcontinent. Ratna, et al. (2016) suggests a weakening of the low-level monsoon westerlies in association with the Indo-Pacific warming should modulate the local Walker circulation. Several studies (Roxy et al. 2015, Krishnan et al. 2016, Paul et al. 2016) point out that the decline in the mean rainfall over central India is consistent with a dampening of the local Hadley circulation, due to a combination of factors including the rapid warming of the Indian Ocean, land use-land cover changes, and increased aerosol content in the atmosphere. Qu and Huang (2012) documented that the tropical Indian Ocean warming since the 1970s has significantly distributed the tropospheric warming over the global tropics. To the east of the equatorial Indian Ocean, the warm anomaly displays a Kelvin wave-like response and to the west a Rossby wave-like pattern, with two maximums off the equator. The Kelvin and Rossby wavelike patterns display the Matsuno-Gill (Matsuno 1966; Gill 1980) pattern, indicating they are the 
responses to the Indian Ocean heating. This tropospheric response is apparent in the anomalous increase in upper-tropospheric geopotential height. A recent study by Jin \& Wang (2017) have shown a revival of ISM after 2002 due to the warming of the Indian continent and slower rate of warming of the Indian Ocean. However, the high resolution rainfall data from the Indian Meteorological Department (IMD) exhibits decreasing trend in the plains of north India even during this period.

The monsoon rainfall over the plains of north India is comparatively less studied with respect to central India. The main objective of this study is to understand the dynamics and the teleconnections of the seasonal summer monsoon rainfall over the plains of north India and the possible reason for the decreasing trend in rainfall during the recent decades, when the rainfall over other regions of India is showing a revival since early 2000. The north India monsoon circulation pattern is poorly understood. In this study, we propose a hypothesis that the decreasing trend in NISR is due to increased SSTs over the eastern equatorial Indian Ocean. This has raised the tropospheric height towards the northeast India, creating low pressure anomalies over northwest India and east Asia with anomalous northerly wind over the Tibetan Plateau. These are unfavorable for NISR. The results of the study are corroborated using numerical model sensitivity experiments.

\section{Data and methods}

The reanalysis products from the European Centre for Medium-Range Weather Forecasts ERA-Interim dataset available at a $0.75^{\circ}$ spatial resolution (Dee et al. 2011) is used for the period 1979-2017. It has been noted that the trends observed in the long-term reanalysis data are 
subjected to artificial shifts due to the introduction of widespread satellite data in the lateseventies (Kinter et al. 2004). Neither data availability nor long-term consistency in data quality is sufficient for detecting and examining this long-term climate trends and/or multi-decadal climate variability (Trenberth et al. 2008). Therefore, the ERA-Interim dataset available after late-seventies-that is, from 1979 till date, is most reliable and realistic. The observed monthly gridded rainfall data over the Indian landmass used in this study is from the Indian Meteorological Department at a resolution of $0.25^{\circ} \times 0.25^{\circ}$ for the period 1979-2017 (Pai et al. 2014). The daily Outgoing Longwave Radiation (OLR) dataset (Liebmann and Smith1996) is used to plot the Wheeler-Kiladis Space-Time Spectra (Hendon and Wheeler 2008) and timelatitude plot to show the equatorially trapped planetary waves (Kelvin and Rossby) and northward propagation of Rossby waves.

The methods used are simultaneous correlation and regression on the detrended dataset. The excess and deficient years are considered +/- 1SD of the long-term mean. For the climate model sensitivity experiments, we use the standard configuration of the Climate Forecast System version 2 (CFSv2), a global coupled ocean-atmosphere model. The CFSv2 model simulates the ENSO and the mean monsoon reasonably well and hence used in this study (Roxy et al.2013). The oceanic component is the GFDL MOM4, at a $0.25-0.5^{\circ}$ horizontal resolution, with 40 vertical levels and an interactive ice model. The atmospheric component is the NCEP GFS, which adopts a spectral triangular truncation of 126 waves (T126) in the horizontal $\left(\sim 0.9^{\circ}\right)$ and a finite differencing in the vertical with 64 sigma-pressure hybrid layers. The atmosphere and ocean model components exchange the heat and momentum fluxes every half an hour, with no flux adjustment or correction. The coupled configuration of CFSv2 is time integrated over a period of 40 years, and utilized as the reference run (CFSv2 $\left.2_{\text {CTL }}\right)$. Ensembles (10 members) of 
short integrations for the summer monsoon season during June-September were performed by adding temperature anomalies to the SSTs passed over the equatorial Indian Ocean, to the atmosphere (CFSv2 $\mathrm{EQIO})$. Positive anomalies of the order of $1.0^{\circ} \mathrm{C}$ was added over the region, in such a way that it tapers out by the limits of the domain $\left(55^{\circ} \mathrm{E}-95^{\circ} \mathrm{E}, 5^{\circ} \mathrm{S}-5^{\circ} \mathrm{N}\right)$. The difference between $\mathrm{CFSv} 2_{\mathrm{EQIO}}$ and $\mathrm{CFSv} 2_{\mathrm{CTL}}$ is taken as the model response to the summer warming over the equatorial Indian Ocean.

\section{Results}

\subsection{JJAS India rainfall trend and atmospheric dynamics}

A study by Jin and Wang (2017)documented the revival of Indian summer monsoon since 2002, but the trend analysis of the seasonal JJAS India rainfall for the period 1979-2017 (Fig. 1a) shows a big patch of the drying trend over the plains of north India. This is consistent with other studies (Ramanathan et al. 2005, Annamalai et al. 2013, Roxy et al. 2015). It is hence intriguing to know why the revival of monsoon is not observed in the plains of north India. The region under consideration consists of Bihar and Uttar Pradesh, two highly populated states of India where livelihood is solely dependent on rain-fed agriculture. The summer monsoon rainfall in this region is comparatively very less studied and poorly understood. However, it is thought that the main component of the rain in this region is the northward movement of the monsoon trough

from its normal position and the interaction between the westerly trough and the monsoonal flow (Ramamurthy 1969, Krishnamurti et al. 1980, Ramaswamy, 1956, 1962, Raman \& Rao 1981, Vellore et al. 2014). Further, to examine the possible reason and cause of this decreasing trend in rainfall over north India and its teleconnections, the time-series has been prepared by averaging 
the gridded rainfall over the box $\left(78.5^{\circ} \mathrm{E}-87.5^{\circ} \mathrm{E} ; 24^{\circ} \mathrm{N}-28.5^{\circ} \mathrm{N}\right)$, named hereafter as NISR. A correlation analysis between NISR and India rainfall shows significant positive correlation coefficients (CC) over most parts of north India (Fig. 1b), but not over other regions. This suggests that the NISR is largely independent of the monsoon rainfall variability over central India or northeast India. The fact that the revival of central Indian monsoon rainfall in the recent decade is not observed in this region illustrates this point. Therefore, this should be studied separately to avoid the results getting obscured due to the rainfall processes over central India and northeast India. Studies in the past have frequently included this region along with the central India or northeast India monsoon domain, which can be misleading. The standard deviation pattern (Fig. 1c) shows $2.4-3.3 \mathrm{~mm} /$ day, suggesting a high variability in this region during summer season JJAS.

Figure 2 shows the regression of 250-, 500- and 850-hPa winds onto NISR (red arrows) and the CC of NISR versus 250-hPa GPH (contours, Fig. 2a) and SST (shaded, Fig. 2e) in the left panels superposed with geographical height over the land. The right panels show 250-, 500and $850-\mathrm{hPa}$ vertical velocity (shaded) and vorticity (contours). The SST pattern (Fig. 2e) shows significant negative $\mathrm{CC}$ over the eastern equatorial Indian Ocean. The eastern equatorial Indian Ocean SST is important as the atmospheric response is largely dependent on the mean SSTs, which are cooler in the western Indian Ocean and warmer in the east. As a result, the response in convection and hence the atmospheric circulation is enhanced even due to slight changes in the eastern equatorial Indian Ocean SSTs. The $850-\mathrm{hPa}$ wind anomaly shows the stronger southwesterlies over Arabian Sea and cyclonic convergence over central/central-east India associated with easterly anomaly over the NISR region. The $850-\mathrm{hPa}$ vorticity (Fig. $2 \mathrm{f}$ ) shows the strong positive vorticity $\mathrm{CC}$ over north India and strong negative vorticity $\mathrm{CC}$ along the foot 
hills of Himalaya towards the northeast NISR region. The strong negative vorticity anomaly in the proximity of foot hills of Himalayan region is due to reflection of winds from the mountains causing divergence. The anomalous wind represents the climatological patterns, revealing strong monsoon trough accompanied with the intense moisture laden easterly monsoonal flow over the NISR region at the lower-level. The negative vertical velocity anomaly at NISR region indicates strong convection. At 500-hPa level (Fig. 2c\&d), the significant easterly wind, vorticity and vertical velocity anomalies over NISR region persist. The CC of 250-hPa GPH (Fig. 2a, contours) shows significant positive CC north-west of India. The winds anomaly (Fig. 2a) shows significant easterly over India and Arabian Sea, and northerly over Tibetan Plateau. The positive GPH anomaly over northwest of India produce anomalous easterly over India and northerly over Tibetan Plateau. Meanwhile, the anti-cyclonic circulation anomaly north of India results in negative vorticity CC north of NISR region (Fig. 2b). Further, the anomalous upper troposphere northerly along the Tibetan Plateau suggests the mid-latitude interaction of dry and cold air with the lower level warm and moisture laden strong monsoonal flow, which incites deep convection and enhanced rainfall over NISR region. In addition, the anomalous winds are easterly from the lower to the upper troposphere over the NISR region, weakening/minimizing the tropospheric wind shear, favorable for deep convection. Over NISR region, the weaker tropospheric wind shear promotes strong convection, while the strong tropospheric wind shear kills the strong convection.

To study the interaction between the lower-level monsoonal flow and the uppertroposphere meridional wind, we have selected two boxes 1) zonal wind over $79.5^{\circ} \mathrm{E}-87.5^{\circ} \mathrm{E}$, $25.5^{\circ} \mathrm{N}-28.5^{\circ} \mathrm{N}$ at the $850-\mathrm{hPa}$, representing the lower-level monsoonal flow, and 2) meridional wind over $84.75^{\circ} \mathrm{E}-97.5^{\circ} \mathrm{E}, 26.25^{\circ} \mathrm{N}-39.75^{\circ} \mathrm{N}$ at the $250-\mathrm{hPa}$, representing the upper-troposphere 
mid-latitude penetration into north India. The CC of NISR with these lower-level zonal wind index and upper-troposphere meridional wind index are -0.48 and -0.33 , significant at $99 \%$ and 95\% confidence levels. Moreover, the CC between the upper and lower troposphere index is 0.43, statistically significant at $99 \%$ confidence level, suggesting the strong association among them and with NISR.

\subsection{Time-series trend analyses}

The NISR time series shows a significant decreasing trend of $-0.03865 \mathrm{~mm} /$ day for the entire study period during 1979-2017, significant at 98\% confidence level (Fig. 3a). The decreasing trend is much larger in the last two decades, from 1996-2017 (-0.0443, period 2), than the earlier period 1979-2000 (-0.02485, period 1). The mean has decreased (from $7.667 \mathrm{~mm} /$ day to $6.986 \mathrm{~mm} /$ day), but the variability has increased (standard deviation from $0.9686 \mathrm{~mm} /$ day to $1.1733 \mathrm{~mm} /$ day) in the period 2 , as compared to the period 1 . This clearly shows the distinction between the two epochs in the NISR, consistent with the recent study (Ratna et al. 2016). Recently, Jin and Wang (2017) reported a short-term increase in the Indian summer monsoon since 2002. This revival is associated with the warming of the Indian continent and slower rates of warming of the Indian Ocean during 2002-2014. Besides, extended SST data until the year 2017 shows significant warming in the Indian Ocean SSTs (Roxy et al. 2017). However, the north India summer rainfall has not revived, but the drying trend has further steepened with increased variability.

The eastern equatorial Indian Ocean SST (EEIOSST) which shows the significant negative $\mathrm{CC}$ over the box $\left(85^{\circ} \mathrm{E}-97^{\circ} \mathrm{E} ; 5^{\circ} \mathrm{S}-5^{\circ} \mathrm{N}\right)$ has been averaged to study its relationship to NISR. The EEIOSST (Fig. 3b) shows a significant increasing trend of $0.0165^{\circ} \mathrm{C} / \mathrm{month}$ 
throughout the data period, significant at 99.9\% level, consistent with other studies (Roxy et al. 2015, Ratna et al. 2016, Abish et al. 2018, Annamalai et al. 2013). The trend is larger in the period 1 in comparison with the period 2. In the period 2, EEIOSST shows a slower rate of warming, but the SST values are always greater than $28.94^{\circ} \mathrm{C}$.

The 21-year sliding CC with NISR (Fig. 3c) shows the secular relationship between NISR and EEIOSST. The relationship shows shift around late-1970s, the CC became significant, with the CC reaching the $98 \%$ confidence level in the last two decades. It is noted that the convection increases with increasing SST, and the rate of increase of convection can be very large for the SST range of $27^{\circ}-28^{\circ} \mathrm{C}$ (Lau et al. 1997). Thus, despite a slower rate of warming in the period 2, the SST anomalies are sufficient enough to anchor the in-situ vigorous convection. In all the deficient years, when the NISR was less than $200 \mathrm{~mm}$, the EEIOSST was greater than $29^{\circ} \mathrm{C}$, such as $1992,2002,2004,2005,2009,2010,2014$ and 2015. In contrary, the flood years, with NISR more than $270 \mathrm{~mm}$, the EEIOSST are less than $28.6^{\circ} \mathrm{C}$, such as 1980 and 1984 . These results confirm a possible relationship between the EEIOSST and NISR.

\subsection{Significant difference between period 1 and period 2}

To study the significant difference in the mean of the two epochs: period 1 and period 2, student's $t$-test analysis has been done on the SST, 250-hPa GPH, 850- and 250-hPa wind, and shown in Fig. 4. The SST (Fig. 4a) shows significant difference over the equatorial Indian Ocean, consistent with studies (Roxy et al. 2015, Ratna et al. 2016, Abish et al. 2018, Annamalai et al. 2013). However, the atmospheric response is largely dependent on the mean SSTs, which are cooler in the western Indian Ocean and warmer in the east. As a result, the response in convection and hence the atmospheric circulation is enhanced over the eastern equatorial Indian 
Ocean, where the north Indian summer monsoon rainfall is significantly correlated. It is argued that the warming in the east equatorial Indian Ocean SST is related to the natural variability of the Indian Ocean, rather than the influence from the Pacific (Abish et al. 2018). The 850-hPa wind shows strong cross-equatorial monsoonal flow over western Arabian Sea and south Indian Ocean, consistent with the study (Ratna et al. 2016). The winds are not significant over India or NISR region. The 250-hPa GPH (Fig. 4b) shows significant increase of GPH over northeast of India associated with anti-cyclonic circulation with southerly wind component over Tibetan Plateau. The rise in anomalous southerly wind component over the Tibetan Plateau in the period 2 hinders the mid-latitude/extra-tropical interaction with the lower level monsoonal flow, which has resulted in enhancing the decreasing trend and increasing the variability of the NISR compared to period 1. Meanwhile, the lower-level monsoonal flow towards the NISR region has not changed significantly. This indicates that the upper-troposphere southerly wind anomalies over the Tibetan Plateau, associated with the negative and positive GPH anomalies over northwest and northeast of India, are responsible for the enhanced decreasing trend in NISR.

\subsection{East Equatorial India Ocean SST}

In order to investigate the influence of EEIOSST on the upper-tropospheric circulation features during period 1 and period 2, we conducted separate correlation analysis between EEIOSST and vertically integrated tropospheric temperature from 650 - to $175-\mathrm{hPa}, 250-\mathrm{hPa} \mathrm{GPH}$ and a regression analysis of $250-\mathrm{hPa}$ winds onto EEIOSST for these two periods (Fig. 4c,d,e\&f). The vertically integrated tropospheric temperature is chosen between 650 - to $175-\mathrm{hPa}$ as the monsoonal latent heating is evident between these levels. Fig. 4c\&d shows that the EEIOSST warming significantly warms the tropical troposphere. To the east of the EEIO, the narrow warm 
anomaly along the equator displays a Kelvin wave response and to the west the widespread warm anomaly along the tropics represents a Rossby wave pattern. Similar type tropospheric temperature warming pattern by the equatorial Indian Ocean SST has been shown by Qu and Huang (2012, Fig. 4b). These Kelvin and Rossby wave patterns display the Matsuno-Gill pattern (Matsuno 1966, Gill 1980). This indicates that the EEIOSST affects the tropospheric temperature through enhanced convection and moist adjustment. These convectively coupled equatorial Rossby and Kelvin waves are the most important in the tropics as they modulate a wide range of weather and climate phenomenon, such as ENSO, monsoons, tropical cyclonic circulation and mid-latitude weather. The Rossby wave exhibit pairs of cyclonic and anticyclonic gyres straddling the equator, which propagates poleward and westward. The Rossby wave displays maximum variability in the northern hemisphere during boreal summer (Huang and Huang, 2011). In the period 2, when the EEIOSST is much warmer than the period 1, the CCs are much stronger. Also, the poleward extension of anomalous tropospheric warming towards northeast India is much deeper and widespread in the period 2 compared to period 1 . This suggests that the stronger convection in the period 2 due to the stronger warming of EEIOSST has generated stronger Rossby and Kelvin waves compared to period 1. The off-equatorial Rossby wave gyres were displaced more poleward, spreading the tropospheric warming more towards the northeast of India in the period 2.

Figure 4e,f CC patterns indicates an elevation of troposphere height over the tropical Indian Ocean, with the maximum anomaly over Bay of Bengal and the warm-pool region of Indonesia due to the intensification of convection over the anomalously warm EEIO. The notable differences are: the negative GPH CC is zonally elongated between $30^{\circ} \mathrm{N}-40^{\circ} \mathrm{N}$ from MiddleEast to east Asia associated with anomalous zonal winds towards the southern fringe of negative 
GPH CC between $20^{\circ} \mathrm{N}-35^{\circ} \mathrm{N}$ in the period 1, while in the period 2 the significant positive GPH $\mathrm{CC}$ has penetrated up to northeast of India forming two negative pressure anomalies over northwest of India and east Asia accompanied with anomalous southerly winds over the Tibetan Plateau. The maximum poleward displacement of off-equatorial Rossby wave gyres towards the northeast of India during period 2 has raised the tropospheric height extending to northeast of India. This clearly displays the notable increase in upper-troposphere GPH towards the northeast of India during period 2 (compared to the period 1, Fig. 4d) due to the warmer EEIOSST during this period (Fig. 3b). It is to be noted that during the period 1 the warm EEIOSST has imposed anomalous westerly over north India. Moreover, in the period 2 the warm EEIOSST has imposed anomalous southerly over the Tibetan Plateau and westerly over north India both, enhancing the decreasing trend and increasing variability of the NISR.

The simultaneous CC between NISR and EEIOSST for the two periods-that is, period 1 and period 2 are -0.144 and -0.49 , respectively. For period 1 the $\mathrm{CC}$ is not significant, while for period 2 the CC is significant at $98 \%$ confidence level. For the entire period-that is, 1979-2017, the CC is -0.274 significant at $90 \%$ confidence level. This indicates that in period 1 when the EEIOSST was below $28.6^{\circ} \mathrm{C}$ the influence of EEIOSST was overlooked, but in period 2 when the EEIOSST increased above $28.6^{\circ} \mathrm{C}$ the in-situ vigorous convection and moist adjustment owing to the SST anomalies affect largely the tropospheric temperature. This affected the uppertropospheric pressure and related wind and thus the NISR.

Further, we have plotted wavenumber-frequency power spectrum (Hendon and Wheeler 2008) for the daily OLR data for JJAS at each latitude and averaged from $15^{\circ} \mathrm{N}$ to $15^{\circ} \mathrm{S}$ (Fig. $5 \mathrm{a} \& \mathrm{~b})$ to extract the equatorially trapped planetary waves: eastward propagating Kelvin and 
westward propagating Rossby waves. To highlight this, we chose two contrasting years, during which SSTs in the east equatorial Indian ocean were high $\left(1992\right.$, SST greater than $\left.29^{\circ} \mathrm{C}\right)$ and low (1980, SST less than $28.6^{\circ} \mathrm{C}$ ), and were non-ENSO years. Both the years shows equatorially trapped eastward and westward propagating Kelvin and Rossby waves, respectively. Now to assess the off-equatorial poleward movement of the Rossby wave west of the warmer eastern equatorial Indian Ocean, we have plotted the time-latitude daily OLR anomaly (averaged over the longitudes $70-77.5^{\circ} \mathrm{E}$ ) for June-September (Fig. 5c\&d). The year 1992 clearly shows more frequent and stronger northward propagation of the cyclonic and anticyclonic Rossby wave gyres. Meanwhile 1980 shows infrequent and weaker northward propagation of Rossby wave gyres compared to the year 1992. Although equatorial Rossby wave can occur at any longitude, the background thermal-dynamics conditions such as warmer SST and larger moisture content favors deep convection and thus the Rossby waves (Huang and Huang, 2011). Therefore, the equatorial warming of eastern equatorial Indian Ocean SST produces stronger northward propagating Rossby waves gyres towards north India in the year 1992 compared to1980.

\subsection{Model results}

In order to confirm the monsoon response to the summer warming over the east equatorial Indian Ocean, coupled model experiments were conducted with SST anomalies (equivalent to the observed trends) imposed over the east equatorial Indian Ocean (Fig. 6a). See Saha et al. (2014)for further details on the model and its components, and Roxy et al. (2015) for a similar numerical experiment setup. The model sensitivity experiments indicate that the warm east equatorial Indian Ocean is associated with strong convection which generates off equatorial Rossby gyres to the west of the convection which spreads up to northeast of India heating the 
troposphere and elevating GPH (Fig. 6b). In addition, in the deep tropics, horizontal variations of GPH are much smaller, since it is difficult to maintain them in the presence of the weak Coriolis force, while in the mid-latitude/extra-tropics the GPH variations are much higher due to the presence of higher Coriolis force. Therefore, in the tropical regions of Indo-Pacific Ocean the GPH positive anomaly is much smaller, while over mid-latitude the anomaly is much bigger respectively. The elevation of GPH over northeast of India has separated two low pressure anomalies over northwest of Indian and east Asia, associated with southerly wind over Tibetan Plateau, consistent with the observation (Fig. 4b). This southerly wind hinders the interaction of upper-troposphere dry winds from mid-latitude/extra-tropical winds to the lower-level monsoonal wind and hence decreasing NISR. The two low pressure areas over northwest of India and east Asia and high pressure area over northeast of India with southerly winds over Tibetan Plateau due to east equatorial Indian Ocean warming, is very well captured by the model and is in agreement with the observation.

\section{Discussion}

The current study focuses on the recent decreasing trend in rainfall during the summer monsoon season (June-September) in north India for the period 1979-2017, when the monsoon has revived in the most part of India since early 2000. Since the Indian monsoon exhibits variability on decadal timescales, and since the analysis period is not long enough to conclude on long-term trends, it is difficult to establish if these observed changes in rainfall are part of natural variability or anthropogenic changes in the climate. Nevertheless, we try to explore the underlying mechanisms dominating the observed changes in the north Indian summer rainfall 
(NISR). The analysis shows that the NISR manifest as the combined contribution of the interaction between the lower-level moisture laden monsoonal flow and the upper-tropospheric dry and cold meridional winds. The low-level monsoonal flow is comparatively warm and moist, and therefore lighter than the upper-tropospheric cold dry air from the mid-latitudes. When these northerly winds from the Tibetan Plateau interact with the monsoonal flow, they uplift the warm and moist monsoonal air as they are lighter than the northerly winds coming from east Asia. Generally, this triggers the deep convection over north India. Also, the Himalayas in the north play the role to steer the winds cyclonic at the lower level, conducive for the convection to occur.

The upper-troposphere meridional wind over the Tibetan Plateau and equatorial Indian Ocean shows substantial difference between the two epochs i.e. first 22-years (1979-2000) and last 22-years (1996-2017). The significant changes in the mean in these parameters show warm SST over the equatorial Indian Ocean, decrease in northerly over the Tibetan Plateau, and decreased rainfall in the later period over NISR. On the other hand, a study by Jin and Wang (2017) reported that a strong warming of the Indian subcontinent accompanied by a slower rate of warming over the Indian Ocean has revived the monsoon over central India since early 2000, due to a strengthening of the land-ocean temperature gradient. The present study reveals that the warming of the eastern equatorial Indian Ocean promotes increased tropospheric moisture to anchor the in-situ convection, generating off equatorial Rossby gyres to the west. This spread tropospheric heating towards the northeast of India, elevating geopotential height (GPH) in the recent decades. The elevated GPH has separated two low pressure anomalies over northwest of Indian and east Asia, associated with anomalous southerly wind over the Tibetan Plateau. This southerly wind hinders the interaction of upper-troposphere dry winds from mid-latitude/extratropical winds to the lower-level monsoonal wind, thereby reducing the NISR. However, the 
changes in Indian Ocean alone may not be responsible for the observed changes in monsoon rainfall. Changes in land cover from trees to crops and changes in land use in the recent decades may also have contributed to the observed weakening of the monsoon, by reducing the evapotranspiration and thereby the recycled component of rainfall (Paul et al., 2016). Also, differential heating in the basins can induce changes in moisture transport, which may also get reflected in the monsoon rainfall over north India (Vishnu et al. 2016). Therefore, land surface processes are important for understanding the changes in monsoon over central and north India. In the present study, we focus only on the effect of ocean warming on the monsoon rainfall, which is significantly large and has a major impact on the monsoon.

Earlier studies suggest that the summer monsoon rainfall is active over north India while the rainfall is subdued over central India, due to a northward shift of the monsoon trough (Ramamurthy 1969, Krishnamurti et al. 1980, Ramaswamy, 1956, 1962, Raman \& Rao 1981). Recent studies (Annamalai et al. 2013, Ratna et al. 2016) argued that the drying of NISR is due to changes in the lower-level circulation. The current study, for the first time, shows that the drying of NISR is due to increase of anomalous upper-troposphere southerly winds over Tibetan Plateau owing to the warm equatorial Indian Ocean in the recent two decades. The north India rainfall is enhanced when the monsoon flow is strong, and the central India rainfall is normal. The strong monsoonal flow gets reflected by the foot hills of Himalayas and produces the cyclonic vortices at the lower level. At the middle to upper tropospheric level the weaker westerly reduces the tropospheric wind shear conducive for the deep convection and allows the frequent interaction of northerly wind from the Tibetan Plateau with the lower-level monsoonal flow, that results in copious rainfall in the region. Though Indian rainfall is available for longterm, high quality ocean-atmospheric data is not available before satellite-era, which is why we 
are restricting this study to post-1979, during which reliable and realistic reanalysis data are available. Considering the rapid and intense warming in the Indian Ocean (Roxy et al. 2014), and given the fact that CMIP5 models project further warming in the Indian Ocean, it is imperative that we pay attention to the remote links and mechanisms explored in this study for improved understanding and prediction of the summer monsoon rainfall.

\section{Acknowledgments}

Commentsof anonymous reviewers dramatically improved the manuscript.Computational and graphical analyses required for this study have been completed with the free software xmgrace, NCL and Ferret.

\section{Data availability}

The IMD gridded data is obtained by writing email to ncc@imd.gov.in and the reanalysis datasets are downloaded from their respective websites. The model data used in this study are available from the contributing author MKR on request.

\section{References}

Abish B, Cherchi A, Ratna SB. (2018). ENSO and the recent warming of the Indian Ocean, Int. J. Climatol. 38, 203-214.

Annamalai H, Hafner J, Sooraj KP, Pillai P. (2013). Global warming shifts the monsoon circulation. Drying South Asia. J Clim 26:2701-2718

Ashok, K., Guan, Z., Saji, N. H., \& Yamagata, T. (2004). Individual and combined influences of ENSO and the Indian Ocean dipole on the Indian summer monsoon. Journal of Climate, 17(16), 3141-3155.

Crétat, J., Terray, P., Masson, S., Sooraj, K. P., \& Roxy, M. K. (2017). Indian Ocean and Indian summer monsoon: relationships without ENSO in ocean-atmosphere coupled simulations. Climate Dynamics, 49(4), 1429-1448. 
Dee DP, Uppala SM, Simmons AJ, Berrisford P, Poli P, Kobayashi S, Andrae U, Balmaseda MA, Balsamo G, Bauer P, Bechtold P, Beljaars ACM, van de Berg L, Bidlot J, Bormann N, Delsol C, Dragani R, Fuentes M, Geer AJ, Haimberger L, Healy SB, Hersbach H, Hólm EV, Isaksen L, Kållberg P, Köhler M, Matricardi M, McNally AP, Monge-Sanz BM, Morcrette J-J, Park B-K, Peubey C, de Rosnay P, Tavolato C, Thépaut J-N, Vitart F. (2011). The ERA-Interim reanalysis: configuration and performance of the data assimilation system. Q. J. R. Meteorol. Soc. 137: 553-597, doi: 10.1002/qj.828.

Gill AE. (1980), Some simple solutions for heat-induced tropical circulation. Quart. J. Roy. Meteor. Soc., 106, 447-462

Goswami, B. N., Madhusoodanan, M. S., Neema, C. P., \& Sengupta, D. (2006). A physical mechanism for North Atlantic SST influence on the Indian summer monsoon. Geophysical Research Letters, 33(2).

Hendon, H. H., and M. C. Wheeler (2008), Some space-time spectral analyses of tropical convection and planetary-scale waves, J. Atmos. Sci., 65, 2936 - 2948, doi:10.1175/2008JAS2675.1.

Huang, P., Huang, R., (2011). Climatology and interannual variability of convectively coupled equatorial waves activity. J. Clim. 24, 4451-4465.

Jin Q, Wang C. (2017) A revival of Indian summer monsoon rainfall since 2002. Nature Climate Change 7: 587-595. Doi:10.1038/NCLIMATE3348

Kinter JLIII, Fennessy MJ, Krishnamurthy V, Marx L. (2004). An evaluation of the apparent interdecadal shift in the tropical divergent circulation in the NCEP-NCAR Reanalysis. J Clim 17:349-361.

Krishnamurti TN, Ardanuy P. (1980). The 10-20 day westward propagating mode and breaks in monsoon. Tellus 32:15-26

Krishnan, R., Sabin, T. P., Vellore, R., Mujumdar, M., Sanjay, J., Goswami, B. N.,\& Terray, P. (2016). Deciphering the desiccation trend of the South Asian monsoon hydroclimate in a warming world. Climate dynamics, 47(3-4), 1007-1027.

Kucharski F, Bracco A, Yoo J, Molteni F. (2008).Atlantic forced component of the Indian monsoon interannual variability. Geophys Res Lett 35:L04706. doi:10.1029/2007GL033037

Kumar, K. K., Rajagopalan, B., \& Cane, M. A. (1999). On the weakening relationship between the Indian monsoon and ENSO. Science, 284(5423), 2156-2159

Lau, K.-M., H.-T. Wu, and S. Bony. (1997). The role of large-scale atmospheric circulation in the relationship between tropical convection and sea surface temperature. J. Climate, 10, $381-392$

Liebmann B. and C.A. Smith, 1996: Description of a Complete (Interpolated) Outgoing Longwave Radiation Dataset. Bulletin of the American Meteorological Society, 77, 12751277.

Matsuno T. (1966) Quasi-geostrophic motions in the equatorial area. J. Meteor. Soc. Japan, $44,25-43$. 
Pai, D.S., Sridhar, L., Badwaik, M.R,, Rajeevan, M. (2014). Analysis of the daily rainfall events over India using a new long period $(1901-2010)$ high resolution $\left(0.25^{\circ} \times 0.25^{\circ}\right)$ gridded rainfall dataset. Clim Dyn. doi:10.1007/s00382-014-2307-1

Paul, S., Ghosh, S., Oglesby, R., Pathak, A., Chandrasekharan, A., \& Ramsankaran, R. A. A. J. (2016). Weakening of Indian summer monsoon rainfall due to changes in land use land cover. Scientific Reports, 6, 32177

Qu X. and Huang G. (2012) An Enhanced Influence of Tropical Indian Ocean on the South Asia High after the Late 1970s. Journal of Climate, 25, 6930-6941. DOI: 10.1175/JCLI-D-1100696.1

Ramamurthy K. (1969). Monsoons of India, some aspects of the 'Break in the Indian southwest monsoon during July and August'. Forecasting Manual No. IV-18.3, India Meteorological Department, Pune, 1-57

Raman CRV, Rao YP. (1981). Blocking highs over Asia and monsoon droughts over India. Nature 289: 271-273

Ramanathan, V., and Coauthors. (2005). Atmospheric brown clouds: Impacts on South Asian climate and hydrological cycle. Proc. Natl. Acad. Sci. USA, 102, 5326-5333

Ramaswamy C. (1956). On the sub-tropical jet stream and its role in the development of large scale convection. Tellus 8: $26-60$

Ramaswamy C. (1962). Breaks in the Indian summer monsoon as a phenomenon of interaction between the easterly and the subtropical westerly jet streams. Tellus 14: 337-349

Ratna S.B., Cherchi A, Joseph P. V,, Behera S.K., Abish B, Masina S. (2016). Moisture variability over the Indo-Pacific region and its influence on the Indian summer monsoon rainfall Clim. Dyn. 46, 949-965

Roxy, M., Tanimoto, Y., Preethi, B., Pascal, T. \& Krishnan, R. (2013). Intraseasonal SSTprecipitation relationship and its spatial variability over the tropical summer monsoon region. Clim. Dyn. 41, 45-61

Roxy, M. K., Ritika, K., Terray, P., \& Masson, S. (2014). The curious case of Indian Ocean warming. Journal of Climate, 27(22), 8501-8509

Roxy, M., Kapoor Ritika, Pascal Terray, Raghu Murtugudde, Karumuri Ashok \& B.N. Goswami. (2015). Drying of Indian subcontinent by rapid Indian Ocean warming and a weakening land-sea thermal gradient. Nature Communication. 6:7423; DOI: $10.1038 /$ ncomms 8423

Roxy, M. K. (2017). Land warming revives monsoon. Nature Climate Change, 7(8), 549.

Saha, S. et al. (2013). The NCEP climate forecast system version 2. J. Climate 27:2185-2208

Saji NH, Goswami BN, Vinayachandran PN, Yamagata T. (1999). A dipole mode in the tropical Indian Ocean. Nature 401:360-363

Trenberth KE, Koike T, Onogi K. (2008). Progress and prospects for reanalysis for weather and climate, Eos. Trans Am Geophys Union 89:234-235

Vellore RK, Krishnan R, Pendharkar J, Choudhary AD, Sabin TP. (2014). On the anomalous precipitation enhancement over the Himalayan foothills during monsoon breaks. Clim. Dyn. 43:2009-2031. doi:10.1007/s00382-013-2024-1 
Vishnu, S., Francis, P. A., Shenoi, S. S. C., \& Ramakrishna, S. S. V. S. (2016). On the decreasing trend of the number of monsoon depressions in the Bay of Bengal. Environmental Research Letters, 11(1), 014011.

Webster PJ, Moore AM, Loschnigg JP, Leben RR. (1999). Coupled ocean-atmosphere dynamics in the Indian Ocean during 1997-98. Nature 401:356-360

Yadav, R. K. (2009a). Changes in the large-scale features associated with the Indian summer monsoon in the recent decades, Int. J. Climatol.29, 117-133.doi:10.1002/joc.1698

Yadav, R. K. (2009b). Role of equatorial central Pacific and northwest of North Atlantic 2-metre surface temperatures in modulating Indian summer monsoon variability, Clim. Dyn., 32, 549-563.doi: 10.1007/s00382-008-0410-x

Yadav, R. K. (2016). On the relationship between Iran surface temperature and north-west India summer monsoon rainfall, Int. J. Climatol. 36,4425-4438; DOI: 10.1002/joc.4648

Yadav, R. K. (2017a). On the relationship between east equatorial Atlantic SST and ISM through Eurasian wave, Clim. Dyn., 48,281-295.doi: 10.1007/s00382-016-3074-y

Yadav, R. K. (2017b). Mid-latitude Rossby wave modulation of the Indian summer monsoon, $Q$ J Roy Meteor Soc, Published Online 2017.doi: 10.1002/qj.3083

Yadav RK, Srinivas G, Chowdary JS; 2018; Atlantic Niño modulation of the Indian summer monsoon through Asian jet; npj Climate and Atmospheric Science; 1:23; DOI: $10.1038 / \mathrm{s} 41612-018-0029-5$

\section{Figure Caption}

Figure 1: IMD data analysis: (a) JJAS seasonal trend analysis for India rainfall. Areas of 95\% significance level are shaded by tiny grey dots. (b) Simultaneous correlation coefficients between NISR and IMD RF data. Areas of 95\% significance level are shaded by tiny grey dots. (c) Standard Deviation of India rainfall (mm/day) for the period 1979-2017. The box represents the NISR region.

Figure 2: Regression of (a) 250-, (c) 500- and (e) 850-hPa wind onto NISR. The grey shading is the altitude. Correlation coefficients of NISR with (a) 250-hPa GPH (contours), (e) SST (color shade), (b) 250-, (d) 500- and (f) 850-hPa vertical velocity (color shade) and vorticity (black contours).

Figure 3: Time-series of (a) NISR (mm/day), (b) EEIOSST and (c) sliding CC on a 21-year moving window between EEIOSST and NISR. The straight black line in a and $b$ represents the trend line for the entire period and the straight dashed line represents the trend line for the respective epochs. The black dash line in c represents the $95 \%$ and $99 \%$ significance levels. 
Figure 4: Student t-test in the mean of the two epochs: 1979-2000 (period 1) and 1996-2017 (period 2) for (a) SST and 850-hPa winds, and (b) 250-hPa GPH and winds. Red contours are significant at $95 \%$ level. Simultaneous correlation coefficients of EEIOSST with (c) vertically integrated temperature from 650- and 175-hPa for (c) period 1 and (d) period 2 and 250-hPa GPH and regression of 250-hPa wind onto EEIOSST (e) period 1 and (f) period 2.

Figure 5: Frequency-wavenumber spectra for the daily OLR data during JJAS for the two extreme years (a) 1992 and (b) 1980. The time-latitude daily OLR anomaly plot (averaged over the longitudes 70-77.5 ${ }^{\circ} \mathrm{E}$ ) for JJAS for the year (c) 1992 and (d) 1980. The black arrows in (c) shows the northward movement of Rossby wave gyres.

Figure 6: Model experiment (a) surface temperature $\left({ }^{\circ} \mathrm{C}\right.$, black contours), rainfall ( $\mathrm{mm} /$ day, color shade), and, (b) 250-hPa wind (m/s, black arrows) and GPH (m, color shade) response. 

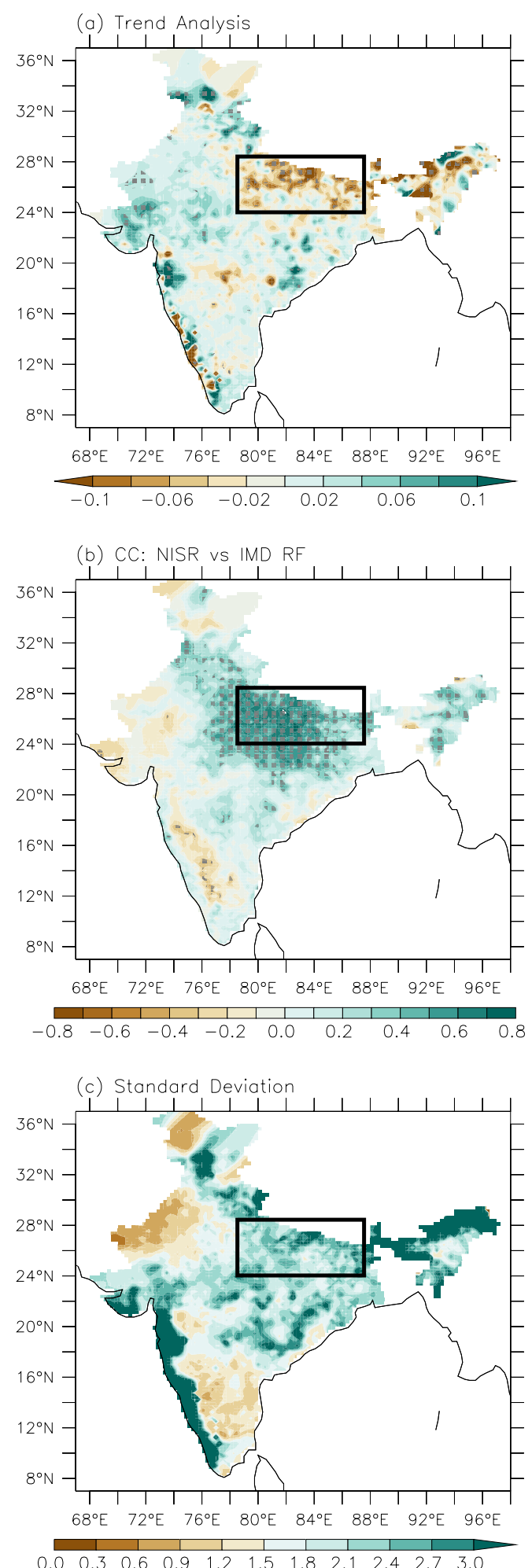

Figure 1: IMD data analysis: (a) JJAS seasonal trend analysis for India rainfall. Areas of 95\% significance level are shaded by tiny grey dots. (b) Simultaneous correlation coefficients between NISR and IMD RF data. Areas of 95\% significance level are shaded by tiny grey dots. (c) Standard Deviation of India rainfall (mm/day) for the period 1979-2017. The box represents the NISR region. 
(a) REG : 250-hPa UV onto NISR

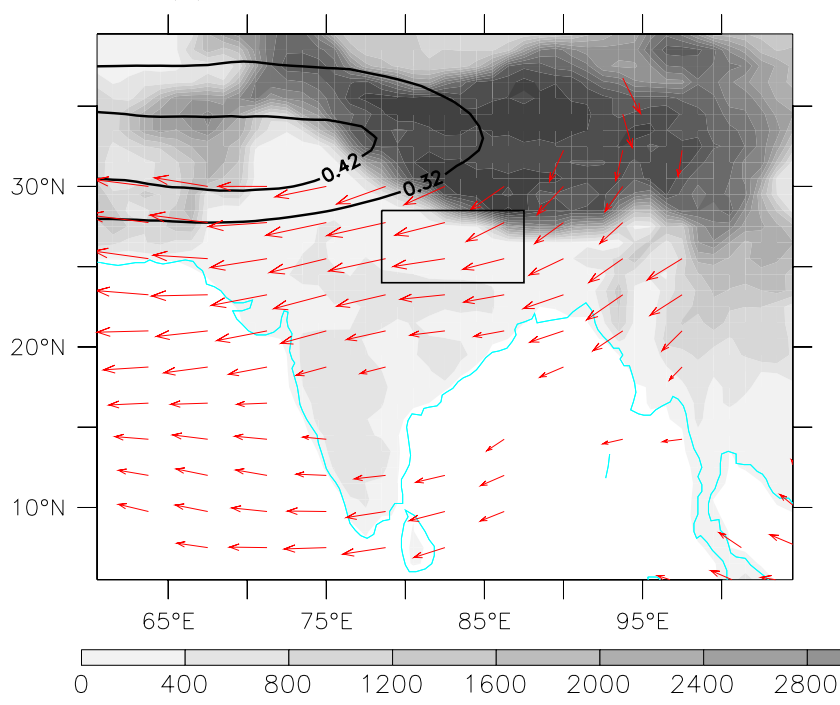

(c) REG : 500-hPa UV onto NISR

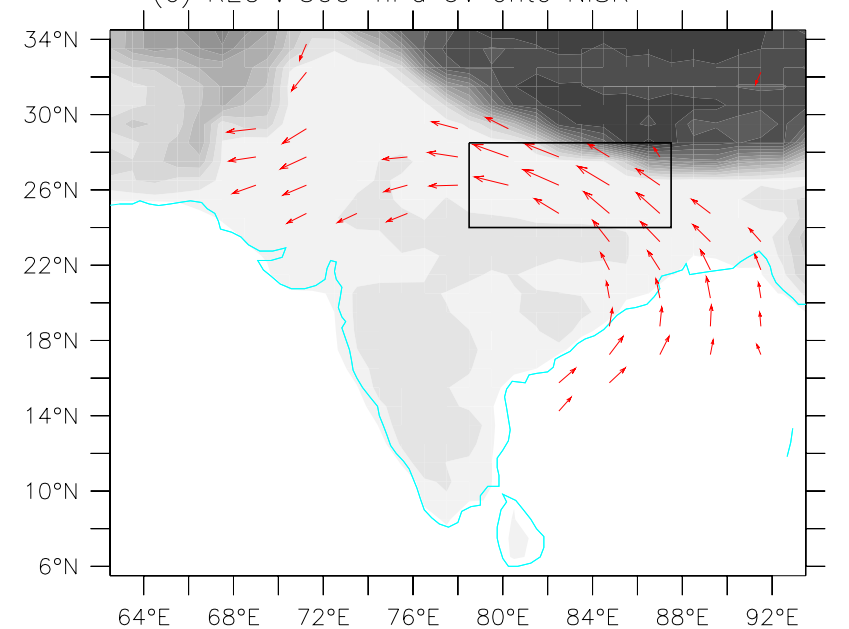

(b) CC: NISR VS 250-hPa VV \& VRX
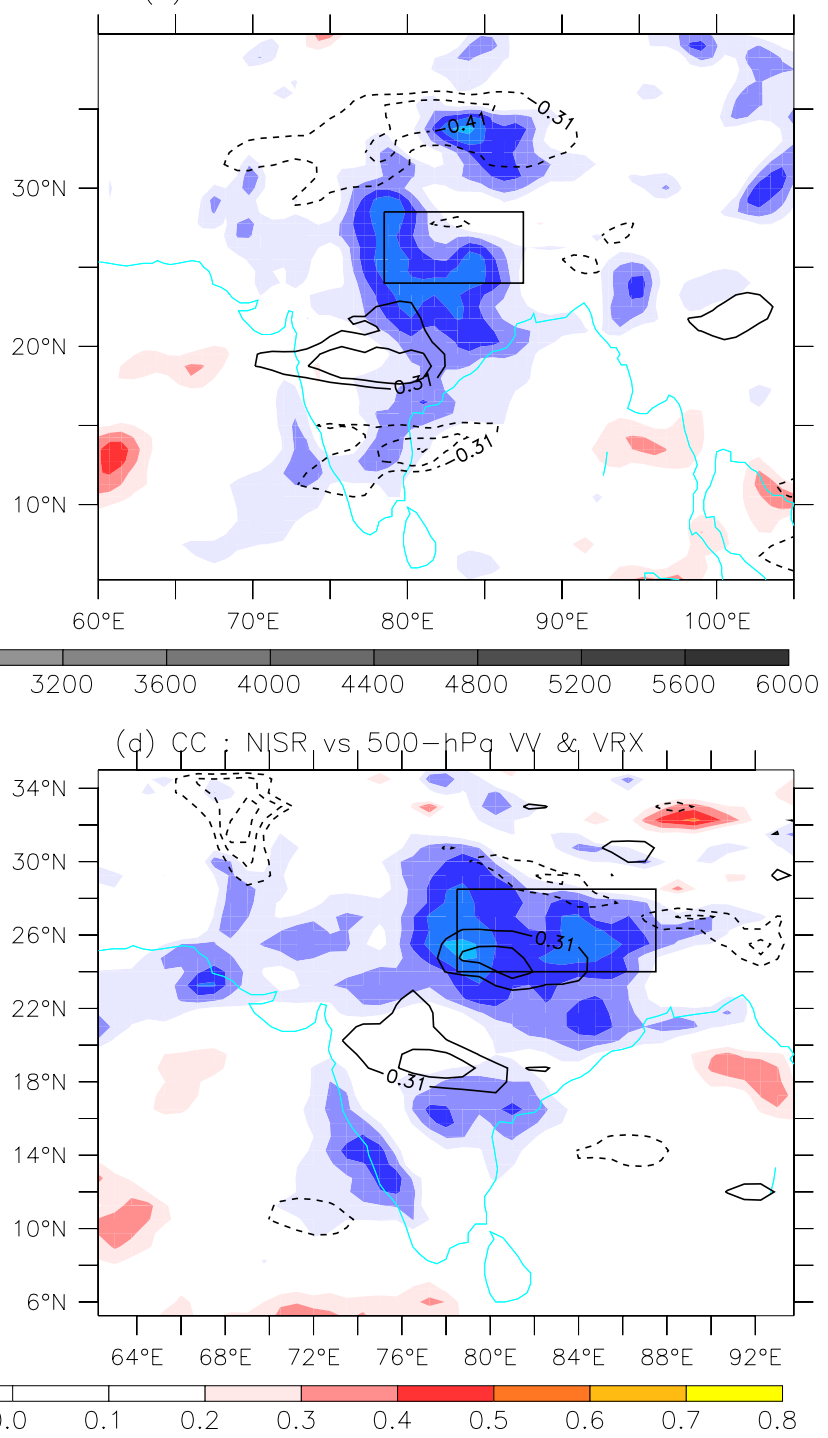

(e) REG : 850-hPa UV onto NISR
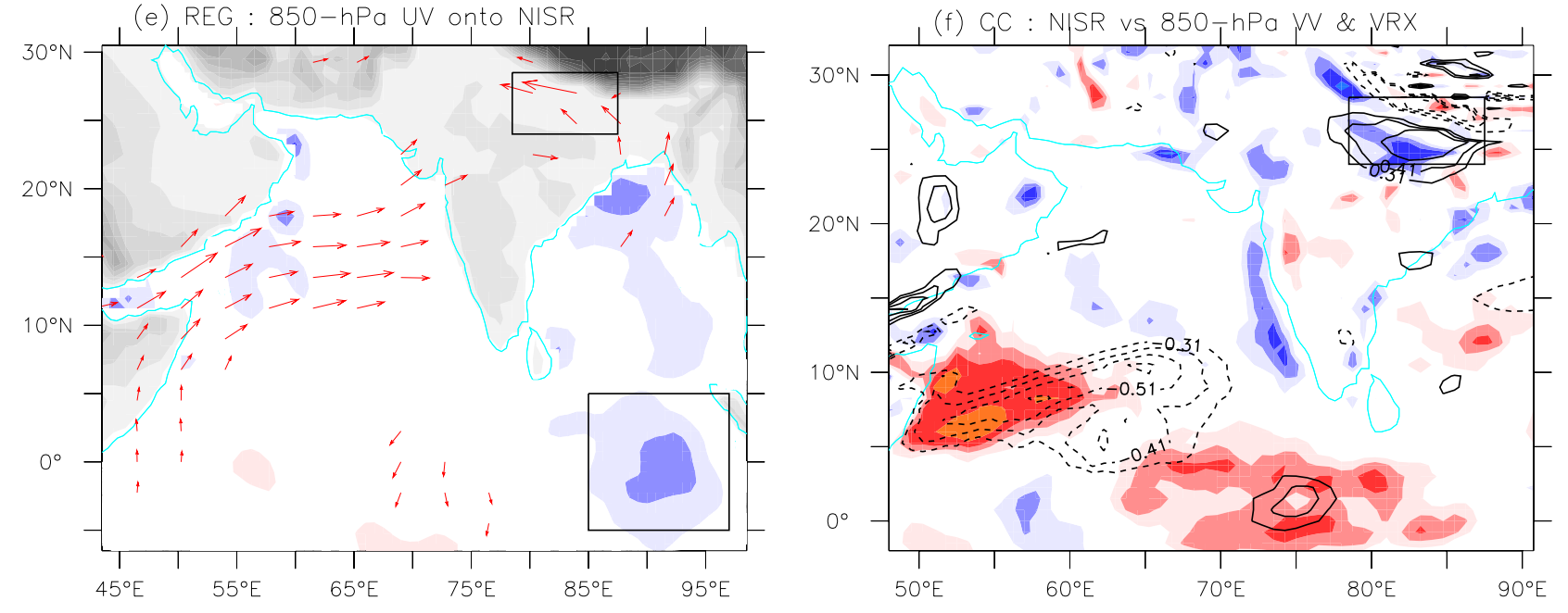

Figure 2: Regression of (a) 250-, (c) 500- and (e) $850-\mathrm{hPa}$ wind onto NISR. The grey shading is the altitude. Correlation coefficients of NISR with (a) 250-hPa GPH (contours), (e) SST (color shade), (b) 250-, (d) 500- and (f) 850-hPa vertical velocity (color shade) and vorticity (black contours). 
(a) NISR

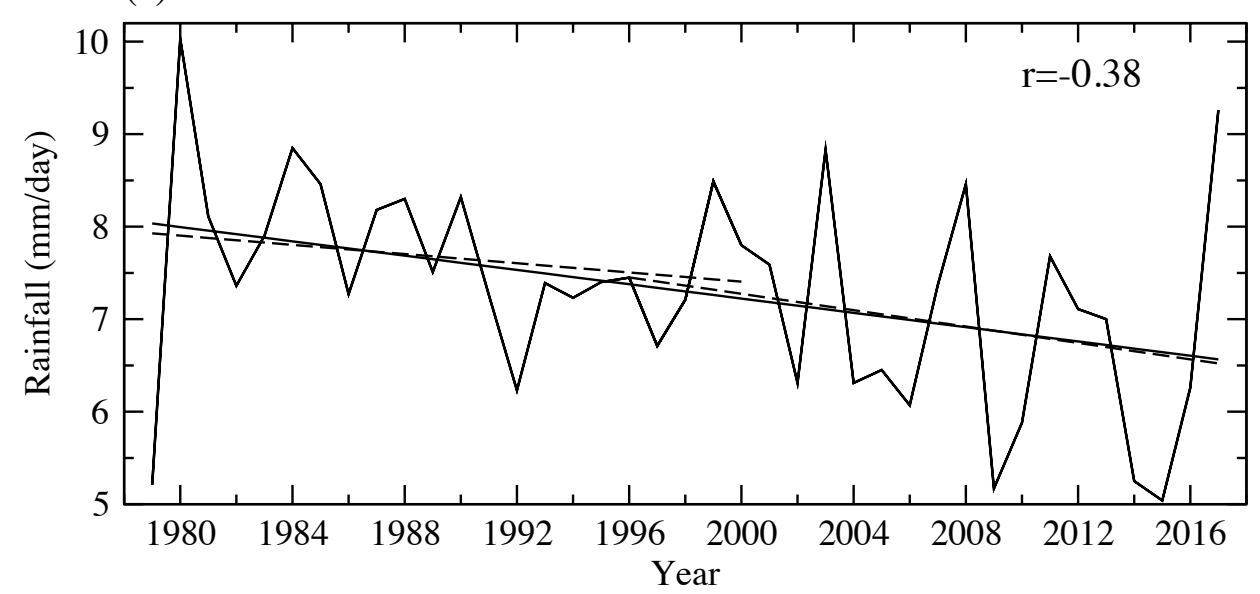

(b) EEIO SST

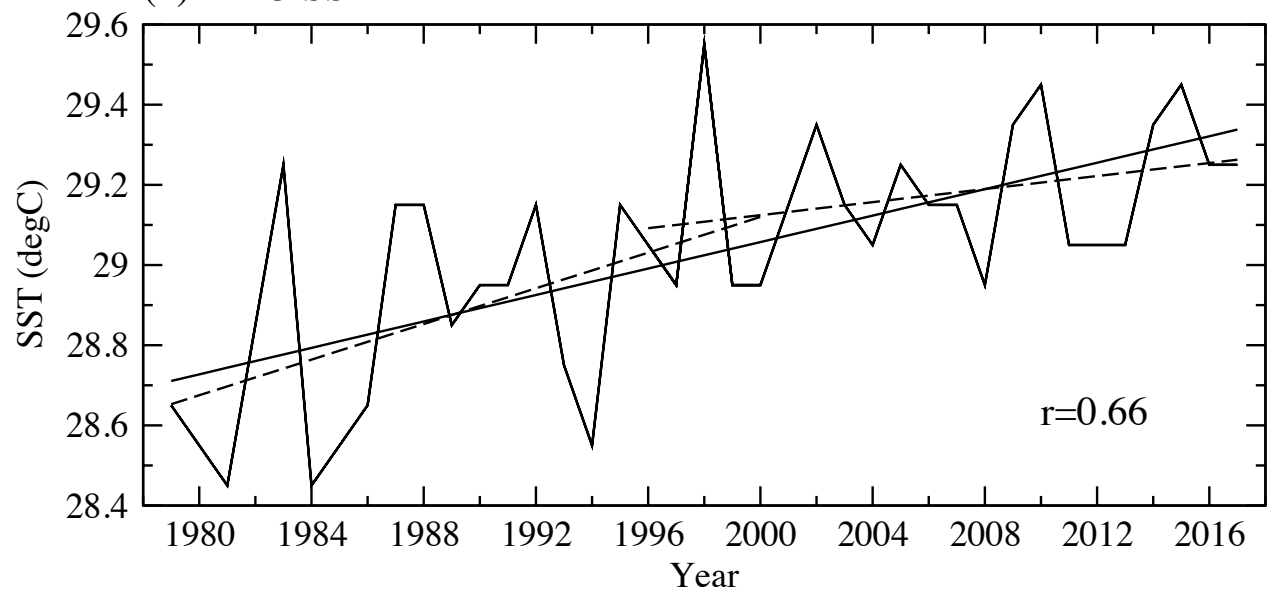

(c) Sliding CC: NISR vs EEIO SST

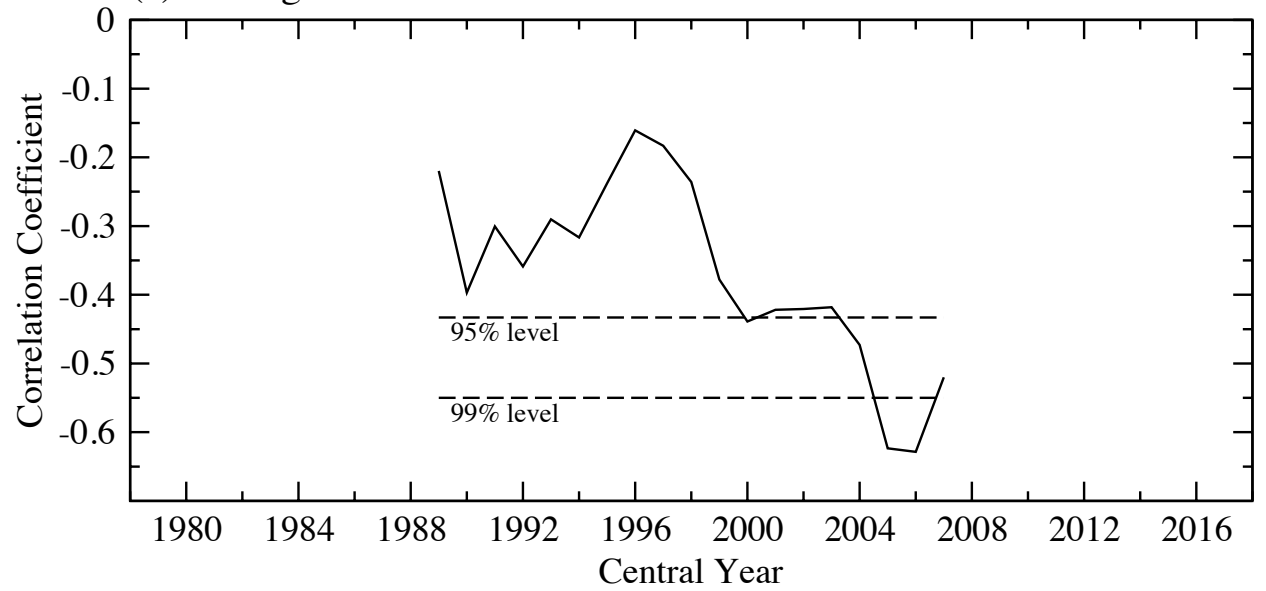

Figure 3: Time-series of (a) NISR (mm/day), (b) EEIOSST and (c) sliding CC on a 21-year moving window between EEIOSST and NISR. The straight black line in a and $b$ represents the trend line for the entire period and the straight dashed line represents the trend line for the respective epochs. The black dash line in c represents the $95 \%$ and $99 \%$ significance levels. 


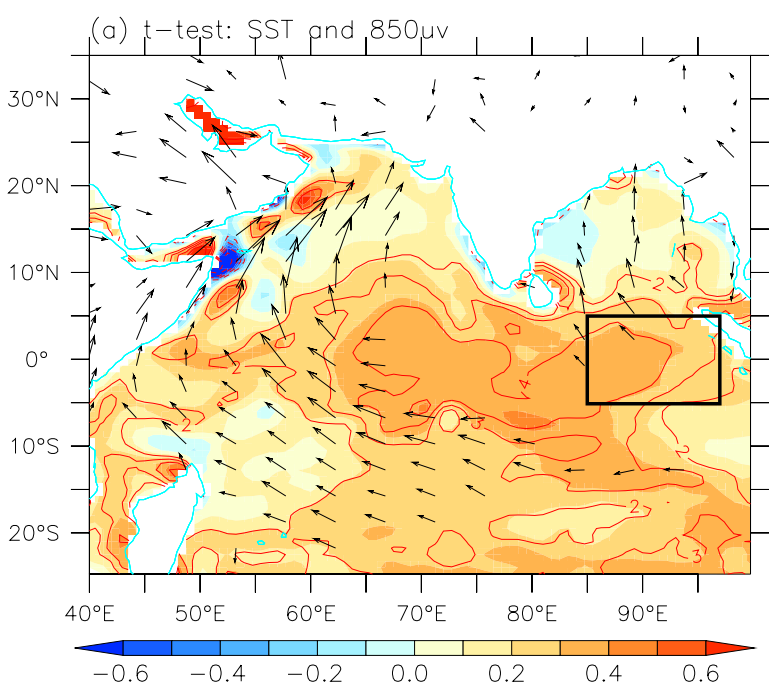

(b) t-test: $250 \mathrm{GPH}$ and UV

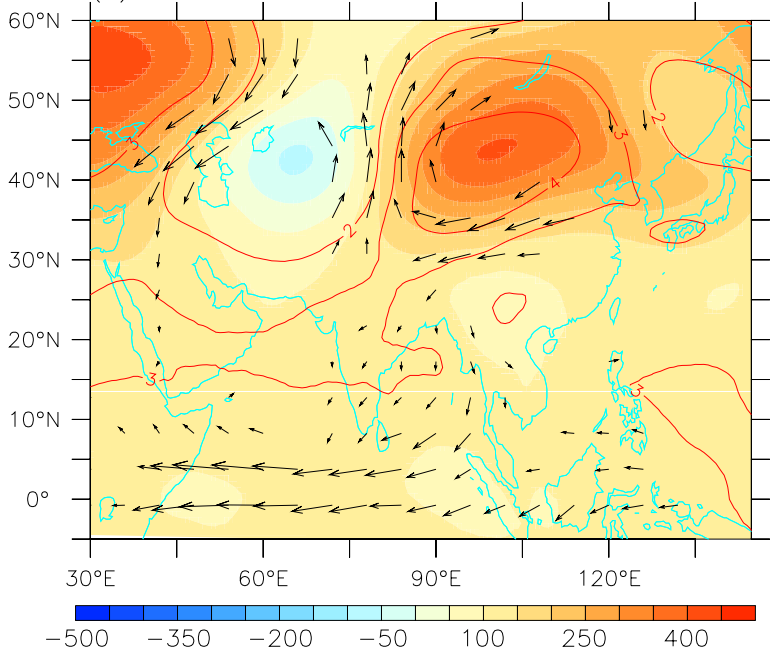

(c) CC (1979-2000): EEIO sst vs VIT

(d) CC (1996-2017): EEIO sst vs VIT
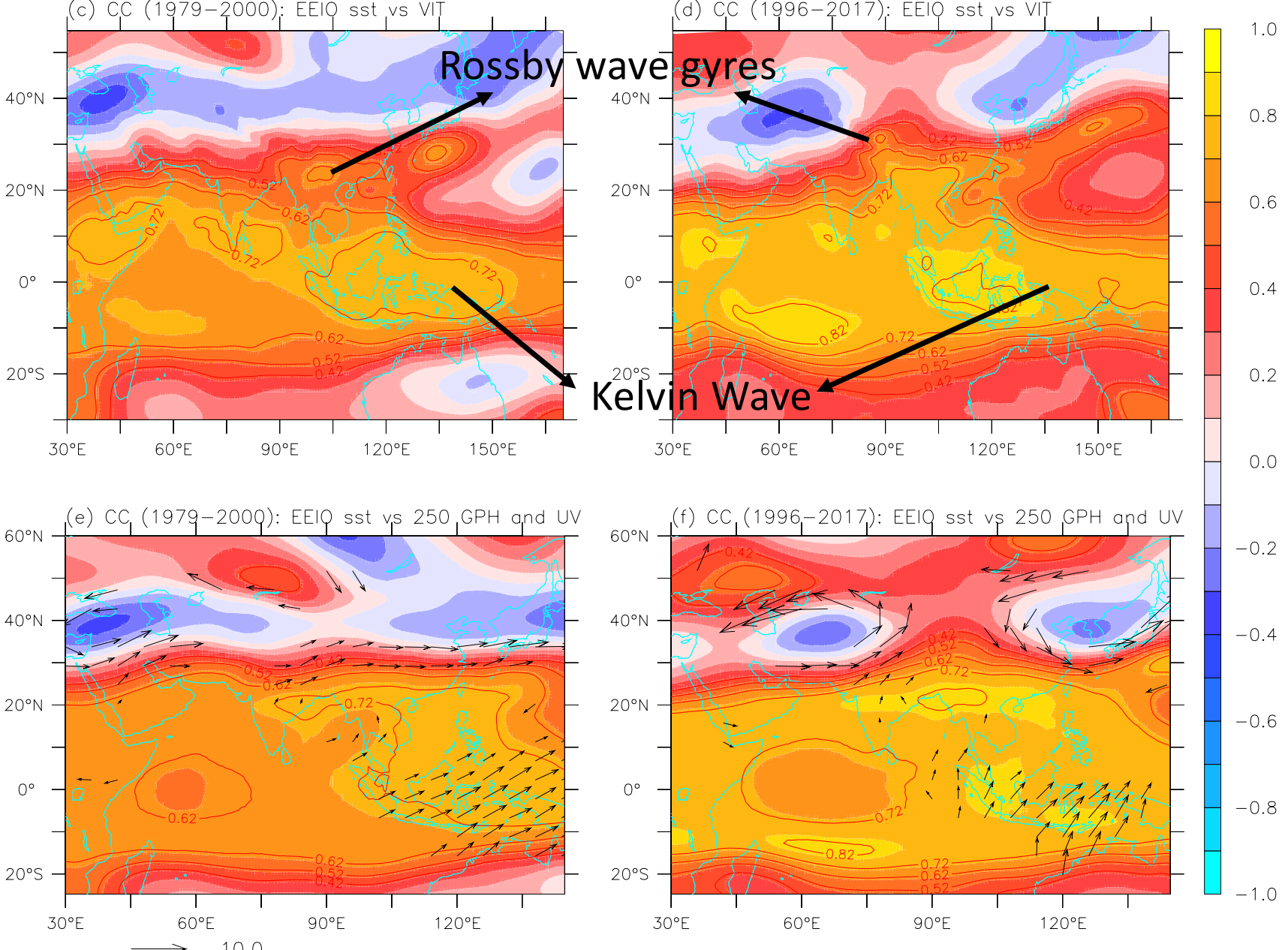

Figure 4: Student t-test in the mean of the two epochs: 1979-2000 (period 1) and 1996-2017 (period 2) for (a) SST and $850-\mathrm{hPa}$ winds, and (b) $250-\mathrm{hPa}$ GPH and winds. Red contours are significant at 95\% level. Simultaneous correlation coefficients of EEIOSST with (c) vertically integrated temperature from 650and $175-\mathrm{hPa}$ for (c) period 1 and (d) period 2 and 250-hPa GPH and regression of 250-hPa wind onto EEIOSST (e) period 1 and (f) period 2. 

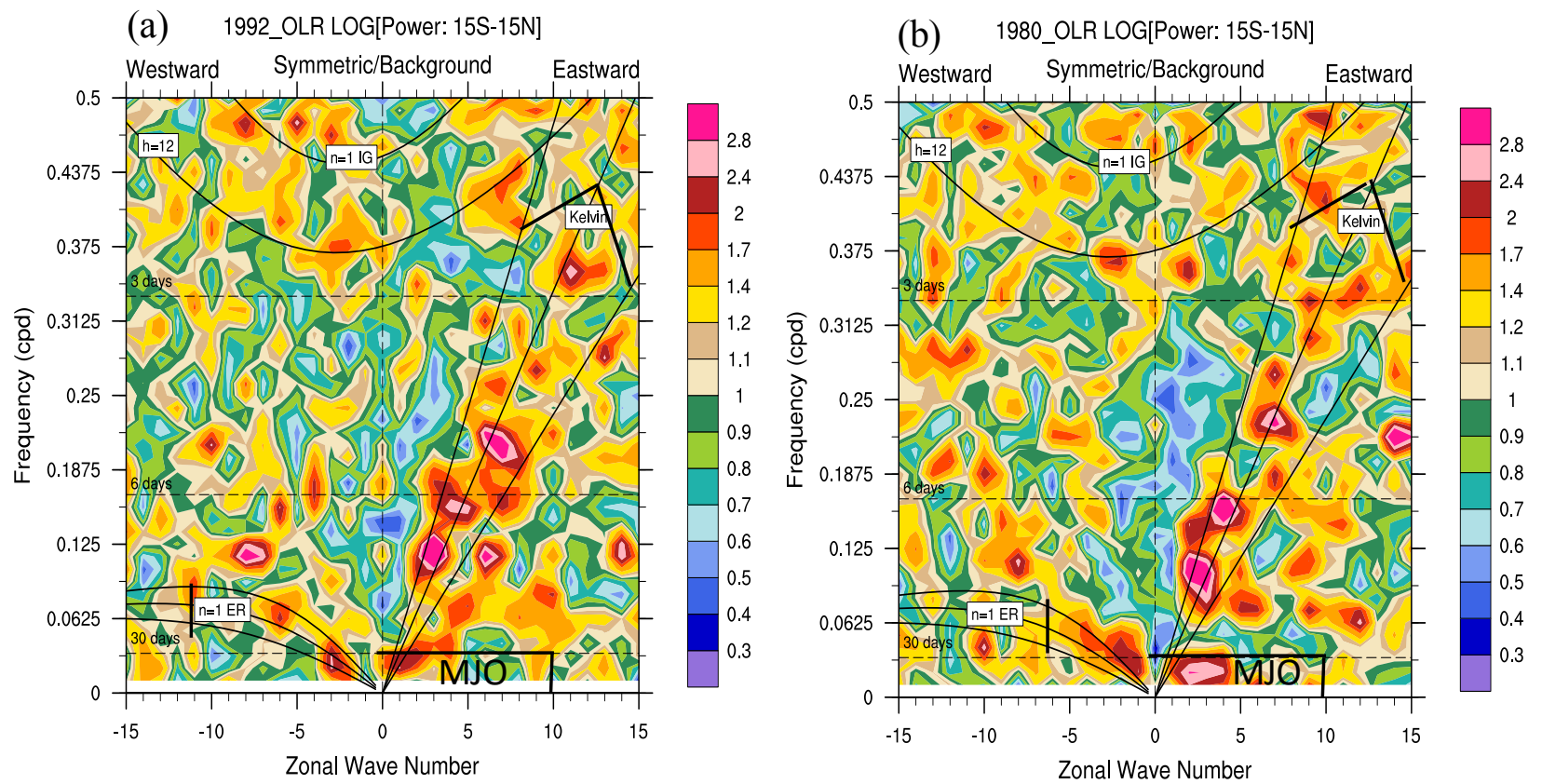

(c) Daily OLR anomaly: 1992

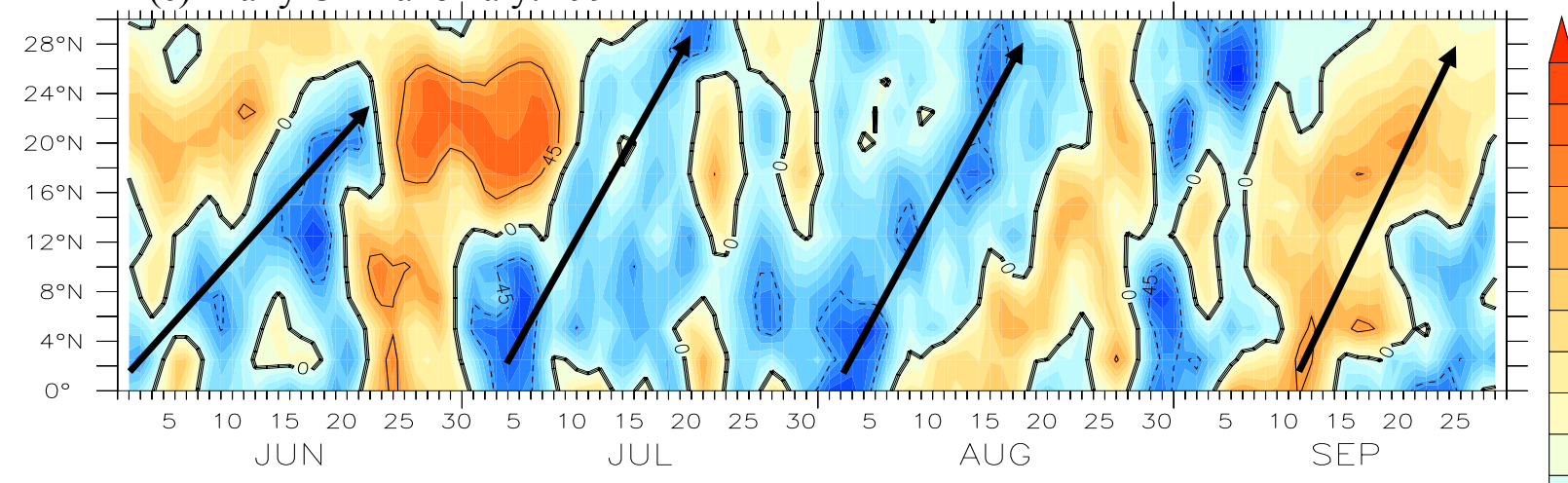

(d) Daily OLR anomaly: 1980

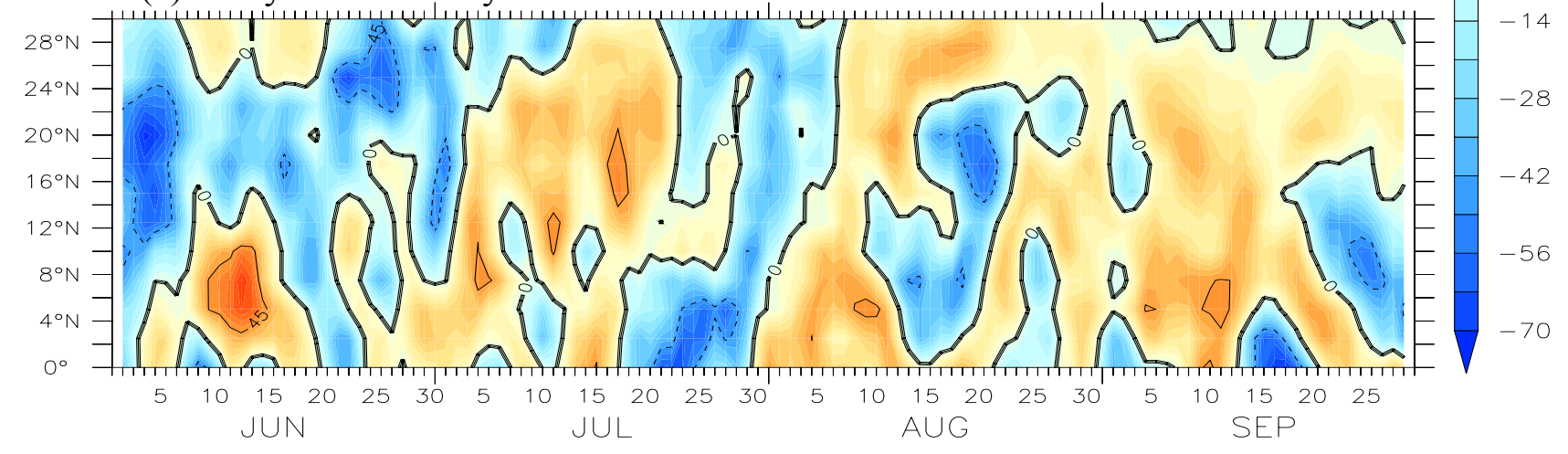

Figure 5: Wavenumber-frequency power spectra for the daily OLR data during JJAS for the two extreme years (a) 1992 and (b) 1980. The time-latitude daily OLR anomaly plot (averaged over the longitudes $70-77.5^{\circ} \mathrm{E}$ ) for JJAS for the year (c) 1992 and (d) 1980. The black arrows in (c) shows the northward movement of Rossby wave gyres. 
(a) Rainfall \& ST response

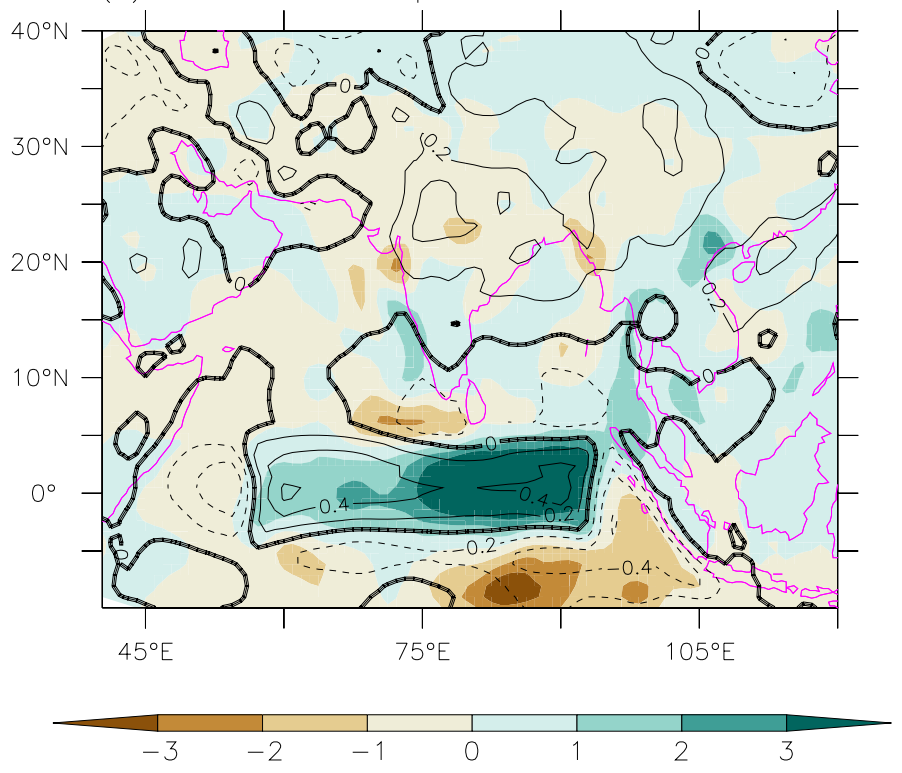

(b) 250-hPa GPH \& wind

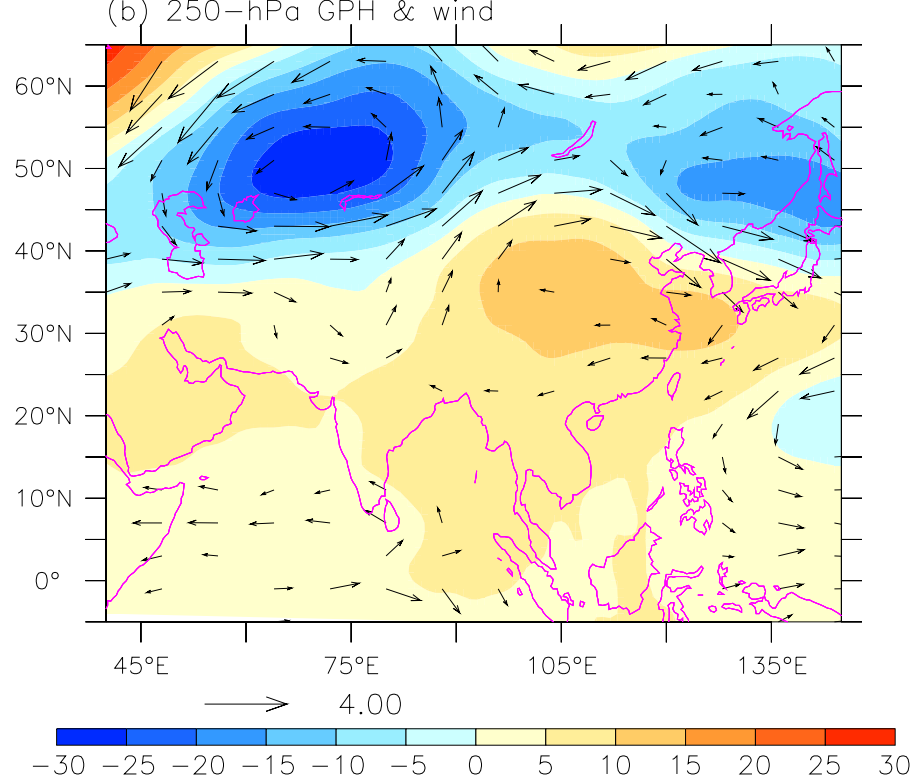

Figure 6: Model experiment (a) surface temperature $\left({ }^{\circ} \mathrm{C}\right.$, black contours), rainfall ( $\mathrm{mm} /$ day, color shade), and, (b) 250-hPa wind (m/s, black arrows) and GPH (m, color shade) response. 